\title{
A Review of COVID-19 Survival Potential in Food and Prevention Approaches
}

\section{A R T I C L E I N F O}

\section{Article Type}

Review Article

\section{Authors}

Mahsa Alikord, $P h D^{1^{*}}$

Ebrahim Molaee-aghaee, $P h D^{1^{*}}$ Mohammadreza Rostami, $P h D^{1}$ Mehri Fallah raufi, $M D^{2}$

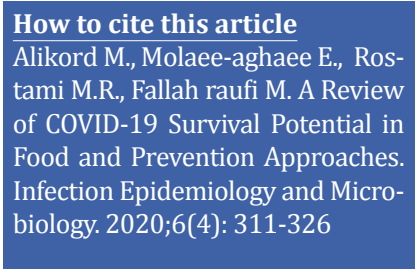

${ }^{1}$ Department of Environmental Health, Food Safety Division, School of Public Health, Tehran University of Medical Sciences, Tehran, Iran. ${ }^{2}$ Faculty of Veterinary Medicine, University of Tehran, Tehran, Iran.

\section{A B S T R A C T}

Background: The new unknown pandemic introduced in December 2019 in China is now known as SARS-CoV-2 induced COVID-19 (Coronavirus Disease 2019) disease. Some studies have been published by World Health Organization (WHO), Environmental Protection Agency (EPA), and Food and Drug Administration (FDA); however, there is a little information about food safety and COVID-19. The world has not sufficiently addressed the effects of COVID-19 on food safety. The remarkable point is the hypothesis that this epidemic has passed through a food source eaten by an individual and subsequently turned humans into an intermediate host. In particular, the recent state of information about SARS-CoV-2 is challenging owing to its high transmission and mortality rate in people as a potential source of pathogen and infections. However, there is currently no evidence about COVID-19 spread through food. Materials \& Methods: Due to the fact that food is a basic humans need and could be an indirect carrier for the virus; therefore, hygiene protocols must be carefully implemented. Also, some studies have suggested that taking supplements, fermented dairy foods, probiotic products, as well as Vitamins C and D could be helpful. Heat treatment and pasteurization could prevent SARS-CoV-2 transmission through food.

Conclusion: It is recommended that further studies be performed on the duration of COVs survival at different levels of contact with foods under certain conditions with nanoparticles, nano-packaging, nano-emulsions, and nano-encapsulation to evaluate their size effect.

\section{Keywords: SARS-CoV-2, COVID-19, Food, Safety, Transmission, Vitamin, Disinfection.}

\section{CITATION LINKS}

[1] respiratory syndrome (SARS) and coronavirus ... [2] Wei X-S, Wang X, Niu Y-R. Diarrhea is ... [3] World Health Organization. Coronavirus Disease ... [4] Forman R, Atun R. 12 Lessons ... [5] Center for ... [6] Food and ... [7] Food and Agriculture ... [8] Food and Drug ... [9] COVID-19 updates ... [10] McClure P. Emerging pathogens of concern in ... [11] Ababouch L. Food ... [12] World Health ... [13] Zhang H, Kang Z ,... [14] Zhou J, Li C, Zhao G, ... [15] Holshue ML, DeBolt C, Lindquist S, Lofy KH, Wiesman J, Bruce H, et al. First ... [16] Letko M,... [17] Cheung KS, Hung IFN, Chan PPY, Lung KC, Tso E, Liu R, et al. Gastrointestinal ... [18] Duda-Chodak A, Lukasiewicz M, Zięć G, Florkiewicz A, Filipiak-Florkiewicz A. Covid-19 pandemic ... [19] Ge X-Y, Li J-L. Isolation ... [20] Hu B, Ge X, Wang L-F, Shi Z. Bat origin ... [21] World Health organization. Animal ... [22] Wei G. Food safety issues ... [23] Yu P, Zhu J, Zhang Z, Han Y, Huang L. A familial ... [24] Belouzard S, Millet ... [25] Lam TT-Y, Jia N, Zhang Y-W, Shum ... [26] Azhar EI, El-Kafrawy SA, Farraj SA, ... [27] Wang L-F, Anderson DE. Viruses in ... [28] Cauchemez S, Nouvellet P, Cori A, Jombart ... [29] Memish ZA, Cotten M, Meyer B, Watson ... [30] Durai P, Batool M, Shah M, Choi S. Middle ... [31] van Doremalen N, Bushmaker T, Karesh WB, Munster VJ. Stability of ... [32] Franklin AB, Bevins SN. Spillover ... [33] Rabenau HF, ... [34] Tian S, ... [35] Zhou P, Yang X-L, Wang X-G, Hu B, Zhang L, ... [36] Gao QY, Chen YX, \& Fang JY. 2019 Novel ... [37] Ceylan Z, Meral R, Cetinkaya T. Relevance ... [38] AW S. Vitamin C protects ... [39] Mongelli L, Golding B. New York ... [40] Martineau ... [41] Wang L, Wang Y, Ye D, Liu Q. Review ... [42] Harthill M. Review: Micronutrient ... [43] Te Velthuis AJ, van den Worm SHE, Sims ... [44] Yin Y, Wunderink RG. ... [45] Ye Z-W, Yuan S, Yuen K-S, Fung S-Y, Chan ... [46] Chan JF-W, Yuan S, Kok K-H, To KK-W, ... [47] Zhu Z, Lian X, Su X, Wu W, Marraro G \& Zeng Y. From SARS ... [48] Hu B, Zeng L-P, Yang X-L, Ge X-Y, Zhang W, Li B, et al. ... [49] Calisher CH, ... [50] Burimuah V, Sylverken A, ... [51] Verani M, Bigazzi R, Carducci ... [52] McDermott CV, Alicic RZ, ... [53] Mao K, Zhang H, Yang Z. Can ... [54] Medema G, Heijnen L, Elsinga G, Italiaander ... [55] Auwaerter ... [56] Kampf G, Todt D, Pfaender S, Steinmann ... [57] Kwok YLA, Gralton J, McLaws M-L. Face ... [58] Cook N. Viruses in ... [59] Zhang Y, Chen C, Zhu ... [60] World Health ... [61] Peng X, Xu X, Li Y, Cheng ... [62] Otter JA, Donskey C, Yezli S, ... [63] Duan S-M, Zhao X-S, Wen R-F, Huang ... [64] 64. World Health Organization ... [65] Aboubakr HA, ... [66] van Doremalen N, ... [67] Environmental Protection ... [68] Shariatifar N, ... [69] Food And Drug ... [70] Food and Drug ... [71] Center for Disease ... [72] Environmental Health ... [73] Rabenau HF, Kampf G, Cinatl J, Doerr ... [74] Saknimit M, ... [75] Dellanno C, Vega Q Boesenberg ... [76] Hudson JB, ... [77] Food Standards ... [78] Food Standards ... [79] Food And Drug ... [80] Food And Drug ... [81] United Nations Industrial ... [82] Center for Disease ... [83] Sportelli MC, Izzi M, ... 


\section{Introduction}

The novel coronavirus (SARS-CoV-2 causing COVID-19 disease), first reported in Wuhan, China has been declared as a global epidemic by WHO [1]. COVs are a family of viruses causing diseases similar to the common cold and respiratory illness, such as Middle East Respiratory Syndrome Coronavirus (MERS$\mathrm{CoV}$ ) and Severe Acute Respiratory Syndrome Coronavirus (SARS-CoV) ${ }^{[2]}$. It could be noted that the new virus is more prevalent than other types of coronaviruses, which could lead to an increased risk of death among people with more susceptibility and chronic illnesses [3]. COVs could survive for several days in different places depending on the type of material surface, as well as temperature and humidity conditions ${ }^{[1}$, 4]. Theoretically, SARS-CoV-2 could not survive in acidic stomach conditions, and studies have shown that there are receptors for the virus in the respiratory and gastrointestinal tracts ${ }^{[5]}$. At present, the discovery of appropriate treatments and vaccines is one of the most important goals of countries. Therefore, prevention is the best way to combat the virus until the discovery of definitive treatments and effective vaccines.

The purpose of this review was to assess some studies on COVID-19 and food safety. Also, attempts were made to provide important tips that could be considered as a concern or research topic to know more about COVID-19 and food safety.

\section{Effect of COVID-19 on food safety and security}

Food safety is part of the definition of food security and has several divisions. Microbial safety, chemical safety, and passive defense, which is a new issue in food safety, are general definitions of food safety. COVID-19 is a potential hazard for life and livelihood. In fact, the situation is unusual and could affect the most vulnerable people in any society as well as important parameters of supply and demand in economics ${ }^{[6]}$. The world demands for maintaining the food supply chains, but the effects of epidemic on the food system have increased problems; for instance, closing borders causes the trade to face problems which restrict people's access to adequate and varied food resources ${ }^{[6-7]}$. The Food and Agriculture Organization (FAO) have stated that some countries have been damaged and are suffering from food insecurity. It is also emphasized that there is enough food for everyone, but the crisis has disrupted food consumption. According to FAO, food supply chains are likely to be disrupted, and less food are produced from high-nutritional value raw materials [7]. Lack of fertilizers as well as veterinary drug and feed could affect the production of agricultural products. Closing restaurants reduces the demand for raw materials hence affects production and suppliers. Therefore, paying attention to adequate food supply and providing access to healthy and adequate food for all segments of society is an important issue for any country and government. FAO has announced recommendations to mitigate the risks of the pandemic ${ }^{[6]}$; for example, countries should meet the immediate food needs of their vulnerable populations and boost their social protection programs ${ }^{[8]}$. In agriculture, animal husbandry, and fisheries, there are some problems about transportation restrictions ${ }^{[9]}$. The impact of this epidemic on animal husbandry is due to reduced access to livestock feed, resulting in reduced production capacity (due to logistical constraints), closure of borders and spoilage of some products such as fish, reduced demand in restaurants and hotels, and reduced people's purchasing power. Thus, all of these factors contribute to limiting access of farmers and fishermen to markets, limiting their production capacity, and reducing the sale of their products. The financial crisis due to lower incomes and uncertainty of income causes people to buy less than their demand. In contrast, the need of each person to have a strong immune system 
in this crisis makes people more willing to buy food products, but they may not be able to buy what they need. This economic downturn is likely to lead to a disproportionate reduction in animal protein consumption due to high prices and even fears that animals may be the hosts of viruses. Accordingly, dietary patterns may change. Subsequently, societies need to pay more attention to food security as well as related issues (Figure 1).

The microbial food safety is important in terms of the microorganisms that cause foodborne diseases or spoilage. These microorganisms include bacteria, fungi, parasites, protozoa, and viruses ${ }^{[10]}$. Foodborne viruses are the leading causes of gastrointestinal diseases in humans. A number of foodborne viruses, including Hepatitis $A$ virus (HAV), Astrovirus, noroviruses (formerly known as Norwalk-like viruses or NoV), and Rotavirus are also associated with some large outbreaks of foodborne illnesses, especially Group B and C rotaviruses and Hepatitis E virus [11]. A general point about food and virus is that food could be the cause of transmission of viruses rather than growth ${ }^{[12]}$. In other words, viruses do not usually grow in food and only survive for some days to be transmitted to their host. This may also be a key question about SARS-CoV-2 transmission through food.

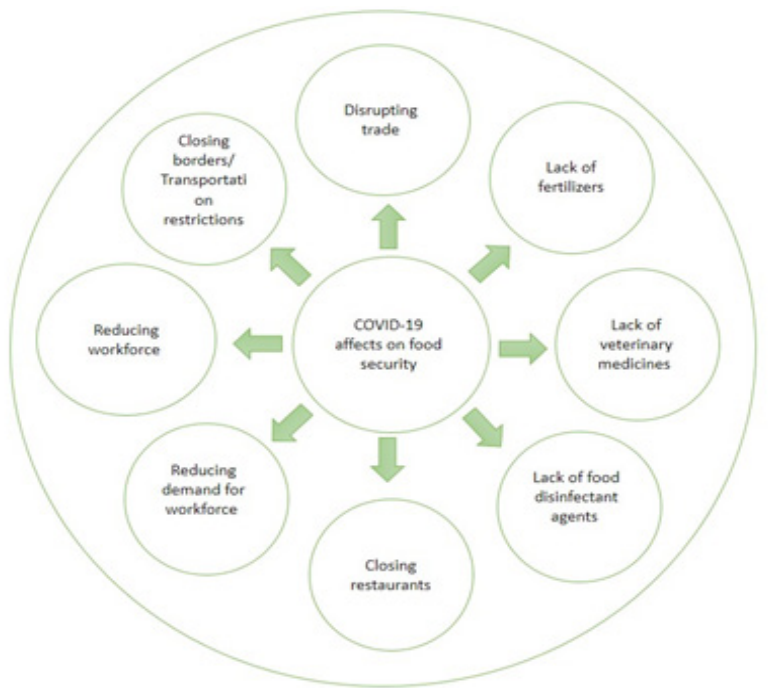

Figure 1) Impact of COVID-19 on food security during the pandemic
The SARS-CoV-2 infection is transmitted when the virus could enter the respiratory and gastrointestinal tracts. This is owing to the ACE2 receptors of SARS-CoV-2, which play an important role in the expression of lung AT2 cells, laryngeal epithelial cells, and epithelial enterocytes of the ileum and colon. Moreover, intestinal symptoms may occur in ACE2-expressing cells. In fact, the respiratory and gastrointestinal tracts are the transmission routes of infection [1314]. Tests of patients with gastrointestinal symptoms have shown a significant amount of the virus in their feces ${ }^{[15]}$. ACE2 receptor is an enzyme that binds to the outer surface (cell membrane) in various organs ${ }^{[16]}$. In February 2020, it was confirmed in China that about $18 \%$ of patients with SARSCoV-2 had gastrointestinal symptoms [17], and RNA of the virus was detected in $48 \%$ of patients ${ }^{[18]}$.

SARS-CoVs have been showed to be isolated from bat (SL-CoV-WIV1) feces containing COVs ${ }^{[19]}$. Thus, bats could be a source of SARS-CoVs. In addition, in Saudi Arabia and some countries, MERS-CoV in bat has been shown to be a global threat to human health. The results of a research showed that three different sequences of SARS-CoVs were capable of using human ACE2 as a receptor. This means that humans are equally vulnerable to these viruses; thus, we must be able to determine future SARS-like illnesses ${ }^{[20]}$. Using search terms [TS = wildlife and food safety (WOS)] and a variety of documents [(Article) Catalogs = SCI-EXPANDED, SSCI Timespan $=2003-2019]$ in Web of Science database, it was found that only 5 studies on food safety were indirectly conducted worldwide. Few of these data are available for academic research worldwide [21-22]. After SARS, the world did not pay enough attention to the safety of food associated with wildlife. Moreover, if COVID-19 is not eliminated, those wild animals full of the 
virus pose other similar potential hazards to the world. Furthermore, the nutritional use of these animals is another factor that should be considered by WHO. It is worth nothing that during the last 17 years, the first SARSCoVs have spread through the consumption of unconventional and wild animals of East Asia origin ${ }^{[22]}$.

Some studies have identified that pangolin could be as a source of the virus due to its use in meat and traditional Chinese medicine ${ }^{[18,}$ ${ }^{23]}$. Despite the sequence similarity between the virus isolated from pangolin and SARSCoV-2 in six key amino acids (RBD), the pangolin-isolated virus is the same as SARS-CoV-2 but with less similarity than the bat-COV (RaTG13)(18). Therefore, it is hypothesized that the virus reached humans a few months before the diagnosis but showed no signs of infection. Studies have also discussed about the replacement of one or more amino acids for protein $\mathrm{S}$ in order for viral entry into new host species [24]. Another hypothesis is that both the pangolin and the bat COVs collided in the same host, e.g., humans; and the changes were made in the genetic formation due to the similarity of many genetic compounds, as a result, the new SARS-CoV-2 virus with a specific genetic sequence identified and severely infected humans as a host ${ }^{[25]}$. Also, there are various hypotheses about how the coronavirus is transmitted from bats to humans ${ }^{[18]}$. As a reservoir of the virus, bats could infect fruits or plants by their feces, urine, or saliva, which then could be eaten by intermediate hosts such as pigs, horses, or human. On the other hand, humans become infected through direct or indirect contact with animals. The COVs have been shown to be transmitted to humans through the saliva, feces, or even milk of infected animals which could be asymptomatic [26-27]. Transmission of COV infection through the mouth has also been confirmed by prior studies on MERS-CoV
[18]. Transmission of contamination through the respiratory tract of camel $(1.5 \%)^{[28]}$ or drinking of unpasteurized camel milk or semi-cooked camel meat $(41.9 \%)$ has also been suggested as a transmission route of MERS-CoV disease [29-30]. Some studies have also assessed the survival rate of MERS-CoV in unpasteurized milk (goat and cow) after about 48 hours [31]. Therefore, consumption of traditional/farm foods without pasteurization should be avoided to prevent foodborne SARS-CoV transmission. It has been shown that heating milk for 30 minutes at a temperature of about $60{ }^{\circ} \mathrm{C}$ is sufficient to inactivate this type of virus [32-33]. Heat treatment reduces MERS-CoV below the detection limit by titration assay; thus, it is a relatively easy and cost-effective measure to prevent transmission.

In the current critical situation, the relationship between food and the virus and its ability to be transmitted through food has been given more attention. One of the general tips for food safety is to have good hygiene when preparing and handling food. Food industry, delivery, retail premises as well as home kitchens are pathways that could increase the possibility of contamination with SARS-CoV-2. Nevertheless, WHO precautions about personal hygiene when preparing food are available, including washing hands before eating food, complete cooking, proper use of meat and animalbased products, covering mouth and nose when coughing or sneezing, and avoiding close contact with food are mandatory. It is better to maintain standard physical distances with anyone who has symptoms of respiratory illness. As mentioned earlier, the food production cycle is very complex. Hence, paying attention to health tips from the first stage of production of raw materials in farms (including livestock care due to lack of adequate studies on the transmission of the virus to animals) to the 
final stage of production of final product as well as to the new GMP approach in health management could be useful. Besides, the stage of purchasing materials from shopping centers, their delivery conditions to home, and the way of receiving and preparing materials for consumption are other points that could be evaluated in the field of food safety. According to the EFSA, there is no evidence showing that food is a source or potential source of COVID-19. Nonetheless, all global organizations emphasize that SARS-CoV-2 is a fat-coated virus; therefore, washing hands with a soap for 30 seconds is sufficient to inactivate the virus ${ }^{[34]}$. Another important point that could be raised in the field of food safety is to pay attention to the continuation of unconventional activities ${ }^{[35]}$.

\section{Nutrition effective in remedying and improving the immune system}

Nutrition is a very important factor in human health. With proper nutrition and diet, people could achieve physical health and boost the immune system. To date, there is no clinical evidence showing that the modification and balance of intestinal microbiota, for example using probiotics, has a therapeutic role in the treatment of SARS-CoV 2, but the National Administration of Traditional Medicine and the National Health Committee of China have suggested the use of probiotics to treat patients with severe infection to sustain intestinal microbiota balance, prevent secondary bacterial infection, and at least treat the disease ${ }^{[36]}$. In this case, taking supplements, fermented dairy foods, as well as probiotic products could be helpful.

The effect of vitamins and micronutrients on SARS-CoV-2 have also been studied. Due to the effect of Vitamin B and A on the immune response, they could be especially useful in people with chronic diseases ${ }^{[37]}$. The effect of Vitamin C in supporting immune functions is also undeniable, and its effect on respiratory diseases may protect individuals against infections caused by CoVs ${ }^{[38]}$. Unlike the first two vitamins, Vitamin $\mathrm{C}$ has been widely studied ${ }^{[39]}$. The effect of reducing the level of Vitamin D on human and Vitamin E on cattle and human CoVs has been proven ${ }^{[40]}$. In this regard, increasing the appropriate intake of supplements with vitamins, especially C, $\mathrm{D}$, and E, may increase resistance to SARSCoV-2 [41]. In micronutrients, deficiency of selenium, pyrite, and zinc could also be effective. The viral genome was shown to be inhibited by these micronutrients to keep cells alive against stress and viral replication ${ }^{[42-43]}$. All of these studies have shown the positive impact of nutritious, healthy, and fresh foods, as well as supplements on human health. Because there is actually a direct relationship between the human immune system and nutrients received through the human diet.

\section{Animal-based food as a potential source of COVID-19}

COVs are classified into alpha, beta, gamma, and delta genera. Bats appear to be predominant carriers for alpha and beta corona viruses, while birds are the predominant carriers for gamma and delta COVs [44]. Alpha and beta COVs are represented as human pathogens (HCoVNL63 or HCoV-229E, HCoV-OC43), which are responsible for colds and diarrhea, or cause asymptomatic infections ${ }^{[44]}$. SARS-CoV and MERS-CoV are beta coronaviruses [18]. Human COVs could cause damage to various tissues and organs ${ }^{[45]}$. However, there is a very important difference between these viruses ${ }^{[46]}$. The transmission rate of SARSCoV-2 from asymptomatic and symptomatic patients is much faster than that of SARS$\mathrm{CoV}$ and MERS-CoV from an asymptomatic patient ${ }^{[47]}$.

There is information about other viruses in the COVs family, including SARS-CoV-1 
and MERS-CoV, most of which are of animal origin. Therefore, there is concern about the exposure to SARS-CoV-2. The remarkable finding about food safety is that COVs have been reported in pigs, cows, horses, cats, dogs, mice, ferns, rabbits, and various species of wildlife, which are often asymptomatic ${ }^{[18]}$. According to FDA and FAO, health measures when dealing with animals could lead to unintended consequences for human health and livelihood ${ }^{[6]}$. The possibility that the disease may be of wild animal origin, such as bats, also raises concerns. To date, there is no evidence of animal-to-human transmission route, but there are few studies showing the transmission of the virus to animals and livestock [22]. Phylogenetic analyses have revealed the highest homology between both SARS-CoV-2 and SARS-CoV-1 (79\% $-82 \%$ ) among other known pathogenic human COVs ${ }^{[18]}$. Also, COVs isolated from bat were more genetically related with SARSCoV-2 ${ }^{\left[{ }^{48]}\right.}$. Some COVs isolated from human samples showed $86.9 \%$ nucleotide sequence identity to bat SARS-like coronaviruses ${ }^{[35] .}$ Zhou et al. (2020) showed that SARS-CoV-2 had 96.2\% whole-genome sequence identity matched to bat COV RaTG13 and more than $88.1 \%$ similarity to bat-SL-CoVZC45. Some studies have also reported that bats could easily spread the virus to other vertebrates, even in remote areas, by flying and migrating long distances and having a long life ${ }^{[49]}$.

Burimuah et al. (2020) determined the prevalence of bovine coronavirus (BCoV) in cattle, sheep, and goats in Ghana. This study identified a significant prevalence rate of $\mathrm{BCoV}$ in Ghana and showed that $\mathrm{BCoV}$ infection in ruminants needs more attention. Many human COVs are known with animal reservoirs. Phylogenetic analysis has shown that $\mathrm{BCoV}$ is of bovine origin and a source of MERS-CoV in camels, its animal-to-human transmission frequently causes lower respiratory tract infections in humans ${ }^{[50]}$.
SARS-CoV-2 is said to be first found in bats. The pathway of transmission is unknown among hosts, but the virus appears to be more contagious in humans. The important point is that sometimes the natural reservoir host tends to amalgamate its viruses, without showing any clinical signs of infection. Nevertheless, completely cooked meat is most likely to be safe to eat. Fish and their products are usually traded domestically, and it is safe to eat products evidenced by safe and hygienic production in accordance with national and international food safety requirements.

The risk of SARS-CoV-2 transmission from infected humans to farm animals and wild animals needs to be investigated as they could act as a repository host for the new virus. Also, the spread of the virus from human and animal feces into the environment could occur through sewage, and its impact on animals and wildlife health is still unknown, but similar human and animal specimens have been observed in the COVs family. Another risk is the possibility of forming new viruses by mutations in new hosts or recombination of SARS-CoV-2 ${ }^{[32]}$. People should not eat or consume animal protein from wild animals. Raw wild animals' meat or uncooked food based on the blood of wild animals should not be eaten. These improper nutritional habits put people at risk for any type of infection. Any side effects or abnormal death of animals should be reported to animal health authorities. FAO, along with a coordinated team, is a regular event for global, regional, and national partners to better understand the potential role of animals and mobilize specialized networks to assess the risk of animal exposure. It is important to prevent livestock disruption due to the widespread prevalence of SARS-CoV-2 in humans. To do this, the organization has provided guidelines for 
farmers and animal health workers.

\section{Environment and disinfection}

It has been observed that patient's gastrointestinal symptoms such as vomiting or flushing the toilet could cause subsequent air transfer through the formation of aerosols ${ }^{[18]}$. Also, in the past, aerosols and vaporization of fecal sewage and wastewater have been reported to be the causes of Adenovirus spread [51]. Recent studies have shown the possibility of spreading fecal virus in the air through various contaminated surfaces ${ }^{[52]}$. From an environmental viewpoint, monitoring wastewater for the presence of the virus may help prevent a new outbreak; thus, the virus could also infect hands and clothing ${ }^{[53]}$. Also, researchers have found SARS-CoV-2 genomic materials in wastewater and river water ${ }^{[54]}$. All of these studies demonstrate the need for paying more attention to proper disinfection of places to prevent the virus spread ${ }^{[8]}$.

Since the beginning of the SARS-CoV-2 pandemic, many studies have confirmed the virus transmission from person to person as direct transmission is the main way for starting an average incubation period (5-6 days or 2-12 days in new host). About two weeks of quarantine are suggested until the infection is gone, but the virus could be asymptomatic for up to 24 days [55]. Transmission from symptomatic and asymptomatic individuals has also been proven ${ }^{[23,46]}$. This means that any direct contact with another person working in a store, market, restaurant, or transportation is a potential peril. Indirect transmission of coronavirus through surfaces contaminated with mucous membranes of the nose, eyes, or mouth emphasizes the significance of accurately monitoring the duration of COVs survival on inanimate surfaces over a period of time, depending on the surface ${ }^{[56]}$. Kwok et al. (2015) reported that people touch their face about 23 times per hour, with $44 \%$ contact with mucous membrane, $36 \%$ with mouth, $31 \%$ with nose, $27 \%$ with eyes, and $6 \%$ with a combination of these areas [57]. Therefore, there is a significant risk of transmission when performing normal daily activities with an asymptomatic patient. Patients (whether symptomatic or asymptomatic) could accidentally infect the environment with the virus after touching their face, and then the virus could be transmitted to other people through their fingers. This could be a potential source of infection in the environment ${ }^{[18]}$. In the food chain, foodstuff may have direct contact with the hands of harvesters on farms, processors, and those preparing food in restaurants and at home ${ }^{[58]}$. Also, as mentioned before, when buying food, most of the ripe fruits and vegetables are carefully selected by the people. Labels cause constant contact of these materials with contaminated or noncontaminated hands. Thus, these are indirect ways of infecting vendors in the store as well as customers. Therefore, thorough washing and disinfection of product surfaces could also be a good solution to reduce the virus, although washing some foods (raspberries, strawberries, and leaves such as lettuce), which have a fragile tissue structure, could be a bit difficult and shorten the shelf life of products ${ }^{[58]}$.

Due to the contamination of dairy products and the transmission of bacteria and viruses, MERS-CoV could survive for a long time in milk [31]. According to EFSA, there is not any proof showing that food is a source and route of transmission of SARS-CoV-2, or that the infection was transmitted through milk [18]. Similar studies have been mentioned in animal and COVID-19 part.

An infectious strain of SARS-CoV-2 isolated from hands, food, or water may be transmitted through feces, oral cavity, 
or respiratory mucosa [59]. Theoretically, SARS-CoV-2 could be transmitted by touching a contaminated surface and then touching the face ( $\mathrm{T}$ point of face including nose, mouth, or eyes). In order to prevent indirect transmission through food, the use of proper hygienic disinfectants and the correct method of hand washing are of great importance. Considering precautionary measures primarily in stores and markets reduces the various factors that cause SARSCoV-2 transmission through foodstuff. In addition, specific methods could be set up to prevent viral contamination, especially for fresh food or packaged food; however, they still need to be implemented even more carefully ${ }^{[60]}$. Interestingly, SARSCoV-2, along with other pathogens such as noroviruses, could not survive on a surface for a long time (weeks), and its stability varies depending on the surface. Also, as mentioned, viruses do not multiply in food, as a means of transmitting viral infectious droplets on the surface of food or packaging, and the amount of virus decreases over time ${ }^{[60]}$. HCoV-E and HCoV-OC43 persist more actively in plasma and blood than on the dry surfaces and are also able to survive in air at room temperature for several days ${ }^{[18]}$. Due to the stability of SARS-CoV-2 on inanimate surfaces, indirect transmission of the virus is possible. It has also been proven that previously known human COVs are able to survive on numerous surfaces ${ }^{[61-62]}$. MERS$\mathrm{CoV}$ is more stable at low temperatures and humidity. In these conditions the virus could be dangerous for about 48 hrs. Therefore, the type of surface, temperature, and relative humidity of the environment are effective factors in viral survival and ultimately transmission rate. In relation to temperature, SARS-CoV was shown to be more stable at room temperature and $4{ }^{\circ} \mathrm{C}$ [63].

The virus persists in feces and urine at room temperature for at least 1-2 days and up to four days, depending on higher $\mathrm{pH}$ conditions. In a study evaluating the stability of SARS-CoVs on various surfaces and in human samples, it was showed that after $60 \mathrm{hrs}$, the infection in the serum began to decrease, and after 120 hrs, it was

Table 1) Different types of biocide agents used for COVID-19

\begin{tabular}{|c|c|c|c|c|}
\hline Biocide Agent & Concentration & Exposure Time & $\begin{array}{l}\text { Reduction of Viral Infectivity } \\
(\log 10)\end{array}$ & Reference \\
\hline \multirow{4}{*}{ Ethanol $^{\circ}$} & $95 \%$ & $30 \mathrm{~s}$ & $>5.5$ & [73] \\
\hline & $85 \%$ & $30 \mathrm{~s}$ & $>5.5$ & [73] \\
\hline & $80 \%$ & $30 \mathrm{~s}$ & $>4.3$ & [73] \\
\hline & $78 \%$ & $30 \mathrm{~s}$ & $>5.0$ & {$[33]$} \\
\hline $\begin{array}{l}\text { Didecyldimethyl } \\
\text { ammonium chloride }\end{array}$ & $0.0025 \%$ & $3 \mathrm{~d}$ & $>4.0$ & {$[56]$} \\
\hline \multirow{4}{*}{ Sodium hypochlorite } & $0.02 \%$ & $10 \mathrm{~min}$ & 0.3 & {$[74]$} \\
\hline & $0.21 \%$ & $30 \mathrm{~s}$ & $>4.0$ & {$[75]$} \\
\hline & $0.01 \%$ & $10 \mathrm{~min}$ & $2.3-2.8$ & {$[74]$} \\
\hline & $0.1 \%$ & $1 \mathrm{~min}$ & & \\
\hline Hydrogen peroxide & $0.5 \%$ & $1 \mathrm{~min}$ & $>4.0$ & {$[56]$} \\
\hline chlorine & $0.5 \mathrm{mg} / \mathrm{L}$ & $1 \mathrm{~min}$ & & {$[68]$} \\
\hline chlorine dioxide & $2.19 \mathrm{mg} / \mathrm{L}$ & $1 \mathrm{~min}$ & & {$[68]$} \\
\hline ozone gas & $20-25 \mathrm{ppm}$ & $1 \mathrm{~min}$ & & {$[76]$} \\
\hline
\end{tabular}


not detectable. SARS-CoV was shown to be significantly reduced in urine after 120 hours. The incubation time was slightly reduced. An important point was the transmission of SARS-COV infection in sputum and feces ${ }^{[64]}$. In the case of inanimate surfaces, the highest stability of SARS was observed on the glass surfaces, which decreased after 120 hrs of incubation at room temperature, while on the wood surface, soil, or water decreased after $60 \mathrm{hrs}$. According to previous in vitro studies on SARS-CoV-2 by WHO, it was found to be more stable than other COVs. Some studies have also been performed on plastic surfaces, showing no difference between the shelf life of SARS862 CoV2 and SARS-CoV-1 on plastic and metal surfaces ${ }^{[31]}$. COVs survive less on copper, nickel, and brass than on stainless steel and zinc surfaces, but SARS-CoV-1 survives on copper for 8 hours, and SARS- CoV-2 shows lower survival rate on copper than SARSCoV-1 ${ }^{[31]}$. At this point, due to the use of stainless steel surfaces in restaurant work environments and inanimate surfaces in packaging, further studies may be needed in this regard. Research shows clothes are not an important source of virus transmission. Because their durability is higher on flat surfaces, while clothes are made of porous materials [65]. Viruses were shown to be also active in some cases after 120 hrs of incubation (metal, cloth, and paper). In the case of air, SARS-CoV-2 was obvious in aerosols up to $3 \mathrm{hrs}$ after contamination and survived $4 \mathrm{hrs}$ on metal, one day on paper, and 2-3 days on plastic and stainless steel ${ }^{[66]}$. Prior studies have shown that the stability of SARS-CoV-1 and SARS-CoV-2 in aerosols and copper was similar. But on paper, the half-life of SARS-CoV-2 was longer than that of SARS-CoV 1. The longest half-life of both viruses was related to the use of stainless steel and plastic, which were 5.6 and 4.2 hrs for stainless steel and 6.8 and $6.6 \mathrm{hrs}$ for plastics, respectively [66]. Reducing the risk of exposure to SARS-CoV-2 by cleaning and disinfecting is a key point that should be taken into account in the reopening of food producing and supplying businesses and requires careful planning in the field of disinfection. If standard detergents and disinfectants are used, SARS-CoV-2 will be killed. Standard disinfectants that could be effective against SARS-CoV-2 have been introduced by CDC, EPH, and WHO because these compounds are able to kill viruses that are harder than SARS-CoV-2. According to all the instructions, regular cleaning with soap and water reduces the amount of virus on surfaces and objects, and this reduces the risk of exposure. It has been shown that SARS-CoV Strain P9 survives and persists at $25^{\circ} \mathrm{C}$ for 4 day on glass, SARS-CoV Strain P9 at $25^{\circ} \mathrm{C}$ for 5 day on metal, SARS-CoV Strain P9 at $25^{\circ} \mathrm{C}$ for $4-5$ day and SARS-CoV Strain GVU6109 at $25^{\circ} \mathrm{C}$ for $24 \mathrm{hrs}$ on aluminum, SARS-CoV Strain P9 at $25^{\circ} \mathrm{C}$ for $4-5$ days and SARS-CoV Strain GVU6109 at $25^{\circ} \mathrm{C}$ for 24 hrs on paper, SARS-CoV Strain HKU39849 at $22-25^{\circ} \mathrm{C}$ for $<5$ days and MERS-CoV (isolate $\mathrm{HCoV}-\mathrm{EMC} / 2012$ ) at $20^{\circ} \mathrm{C}$ for $48 \mathrm{~h}$ or $30^{\circ} \mathrm{C}$ for 8-24 hrs on plastic [56,68]. Disinfectants that are both available in food safety and studied by international organizations are listed in Table 1. The usual disinfectant is 5 tablespoons ( $1 / 3$ cup) bleach per gallon of water (or 4 teaspoons bleach per quart of water for $1 \mathrm{~min}$ ) or $70 \%$ alcohol solution. Importantly, bleach solutions are effective for up to 24 hrs for disinfection. Besides, frequent disinfection of surfaces and objects by people is important $[3,9,69-$ ${ }^{72]}$. One of the important points when using disinfectants is that they should be stored and used according to the label. In the case of bleaching agent, it should not be mixed with other cleaners because it could cause the production of vapors that are very dangerous to breathe ${ }^{[72]}$. 
Food safety management systems as a preventative way in food industry

In an outbreak, it is important for every food industry to follow a set of standards and safety precautions or to have the protocols of Food Safety Management Systems (FSMS). In fact, these are the premise of the HACCP principles that have been updated in times of crisis. During the global COVID-19 epidemic, it is more important than ever that companies comply with current HACCP principles; for example, new good manufacturing practice (GMP) instructions should be in accordance with the highest production standards ${ }^{[77]}$. Despite announcements of FDA in recent months to postpone further inspections of foreign facilities and routine monitoring of domestic facilities, the global manufacturing industry should be prepared for the oversight of the Food and Drug Administration ${ }^{[8]}$. During the pandemic of SARS-CoV-2, companies have to make certain guidelines. These include conducting internal audits following GMPs and increasing surveillance in specific areas that may be related to SARS-CoV-2. For example, companies need to train their employees to prevent the spread of disease and provide regular updates on SARS-CoV-2 improvements. It may also be necessary to develop more accurate protocols for employees' hygiene, equipment hygiene, and even employees' quarantine. Reducing the number of employees in factories could also be effective. Also, temporary performance could provide opportunities for activities such as cleaning. Temporary policies on packaging and labeling by retail stores are also required in the event of public health emergency of COVID-19 pandemic, and working remotely may be an ideal option for most individuals ${ }^{[60]}$.

Unlike gastrointestinal viruses such as Norovirus and Hepatitis $A$ transmitted by contaminated foods, in case of SARS-CoV-2, it is not clear whether food or livestock are exposed to the virus. The FDA and CDC have detailed guidelines on their website to ensure that foodborne illnesses are not spread during the pandemic of SARS-CoV-2 [11]. But perhaps a long time without a mask in a public place such as restaurants could be one of the factors that cause the spread of the disease.

The announcement of production plants should be registered by FDA of each country (in that city or province) $[8,60,77$ ${ }^{78]}$. It is considered that faster reporting of more specific information about some food manufacturers (factories, retail premises) could improve the current state of food supply and challenges facing production. Reporting and requesting protocols should be provided on the website of FDA of each country under the heading of starting work in critical situations. Some instruments should be applied and monitored. There are some tips to help food manufacturers, such as determining what needs to be cleaned and what disinfectants to use, as well as developing, implementing, revising disinfection plan. Also, other points are as follows, people should be at 6 feet distance when talking, checking the body temperature before entering the factory gate (anyone with a temperature above $99.5{ }^{\circ} \mathbf{F}$ is not allowed to enter), wearing mask or personal protective equipment (PPE) throughout the factory, increasing ventilation and the percentage of outdoor air circulation inside the system, removing all intact repairs or doors that need contact to open, identifying areas that require restricted access during and immediately following enhanced cleaning, and moving from 1 or 2 shifts to 3 shifts and keeping each shift with the same people every day. If one shift is sick, it should be protected. The plant is set up to prevent employees from wandering into areas where they do not need to work, and key 
personnel who are unable to work should be separate from the plant (e.g., boiler operators, wastewater treatment engineers, electricians, maintenance workers, etc.); to prevent them from getting sick, start, stop, rest, and lunch times should be changed to minimize break hours or areas ${ }^{[60]}$.

Necessary facilities for washing and disinfecting of personnel should be used to maintain clean the food contact surfaces $(60,64)$. A specialist should be appointed for counseling during an epidemic. The correct method of washing, proper physical distance, and symptoms of the disease should be taught correctly ${ }^{[79]}$. If it is confirmed that an employee has SARS-CoV-2, employers must notify other employees of their possible exposure to SARS-CoV-2 at work. The patient must follow the CDC guidelines, and employers must consult with FDA of the local health department for further guidance. The use of disinfection and sanitation services and regular disinfection of food contact surfaces is essential. The FSMS regulations could be effective in controlling foods. Important points are as follows: (1) it is necessary to prepare food for the use of "disinfectant" products that have been registered with the environmental protection agency during the

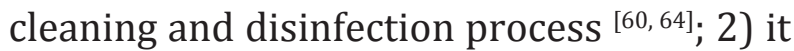
is necessary to use a product on the list of "disinfectant" products registered by EPA for SARS-CoV-2, which is available under the viral pathogen EPA program for use against SARS-CoV [67].

\section{Quality control (QC) or quality assurance (QA) in food safety about COVID-19}

Quality assurance and quality control are two aspects of quality management. Whereas some quality assurance and quality control activities are interrelated, the two are defined differently. Quality assurance could be defined as "part of quality management focused on providing confidence that quality requirements will be fulfilled". The confidence provided by quality assurance is twofold-internally to management and externally to customers. Quality control could be defined as "part of quality management focused on fulfilling quality requirements". While quality assurance is related to how a process is performed or how a product is made, quality control is more the inspection aspect of quality management. An alternate definition for quality assurance is "the operational techniques and activities used to fulfill requirements for quality." The product may be shipped from a quarantine site, there must be a system to ensure that the product does not enter the market until QC is approved. Therefore, it is necessary to determine a temporary policy, test workers with suspected positive symptoms, and examine the supply chain of raw materials for products prepared with a thermal process below $70{ }^{\circ} \mathrm{C}$ of food facilities ${ }^{[60,70]}$. Food manufacturers must coordinate with local health authorities and be able to provide accurate and timely information at any time and place. Re-testing of raw materials is allowed depending on the sensitivity of the materials as well as the quality control strategy of the final product and the release date ${ }^{[80]}$. The inspection should be carried out regularly and focus on data integrity in GMP inspections and ensure that all data related to "safety, efficacy, and quality" are "safe and accurate". Computer output should be paid attention in terms of "checking accuracy", proving and completing backup of unwanted changes, deleting or disappearing, and "special" timely "documentary activities. In case of non-compliance, FDA must inform organizations about the punishment and its consequences; also, companies must provide a written action plan within 15 days and immediately implement their plan [81]. There should be a penalty approach in the 
warning letters in the organization's official announcements for identified serious violations, unless the company quickly and extensively modifies problems and hazards [82].

The CDC also has protocols for food retailers. The pandemic has caused significant changes in consumer food buying behavior. While food consumption has suddenly declined in large centers such as hotels, restaurants, stadiums, and universities, food demand has increased in grocery stores. The FDA has issued temporary guidelines to support consumer, food supply chains, and retail market ${ }^{[79]}$.

\section{Conclusion and future perspective research}

COVID-19 and the importance of its transmission through food and food packaging should be given more attention. Preventing and monitoring the incidence of animal-based foodborne illnesses should also be on the global agenda. Furthermore, the reopening of food producing businesses according to health protocols as well as monitoring and documenting FDA information by quality control managers could help reduce the rate of pandemic. The proposals that have been put forward in this regard have caused food and environmental safety experts to have concerns about the fate of this recommendation and suggestions. Therefore, a number of questions that have been asked about this virus and the health protocols could engage the minds.

Many methods are used to inactivate viruses in food. These methods are sometimes traditional, such as baking with a high temperature. The use of some other methods such as radiation in doses of 2 to $3.0 \mathrm{KG}$, ultraviolet light of $245-285 \mathrm{~nm}$, and high pressure processing of about 300-400 $\mathrm{MPa}$ at $5-22{ }^{\circ} \mathrm{C}$ for $5 \mathrm{~min}$ are located in the middle of the success path ${ }^{[68]}$. In recent years, an alternative active and intelligent method has been considered in this field such as the application of nanoparticles in food packaging. The effect of metal ions on inactivating some viruses has also been proven. In a study performed on the effect of nanomaterial coatings or films containing copper, silver, and zinc nanoparticles against SARS-CoV-2, good results were obtained ${ }^{[83]}$. Therefore, further studies on the duration of COVs survival at different levels of contact with foods under certain conditions are required.

\section{Acknowledgment}

Authors thank Tehran University of Medical Sciences Services.

Ethical Permisions: Not Applicable.

\section{Conflict of Interest}

The authors declare no competing financial interest.

Authors' Contribution: Conceptualization: MA; Data curation and formal analysis: MA; Investigation: MA; Methodology and project administration: MA; Supervision: MA, EMA; Validation: MA, EMA; Writing of original draft: MA, MRR, MFR; Writing, reviewing, and editing:MA:

Fundings: There was no funding. Consent to participate: Not Applicable.

\section{References}

1. Law S, Leung AW, Xu C. Severe acute respiratory syndrome (SARS) and coronavirus disease-2019 (COVID-19): From causes to preventions in Hong Kong. Int J Infect Dis. 2020;94:156-63.

2. Wei X-S, Wang X, Niu Y-R, Ye L-L, Peng W-B, Wang Z-H, et al. Diarrhea is associated with prolonged symptoms and viral carriage in coronavirus disease 2019. Clin Gastroenterol Hepatol. 2020;18(8):17539

3. World Health Organization. Coronavirus Disease (COVID-19) Dashboard. World 
Health Organization; 2020.

4. Forman R, Atun R, McKee M, Mossialos E. 12 Lessons learned from the management of the coronavirus pandemic. Health Policy. 2020;124(6):577-80.

5. Center for Disease Control and Prevention. Coronavirus disease 2019 (COVID-19). FEMA; 2020.

6. Food and Agriculture Organization. COVID-19 pandemic - impact on food and agriculture. FAO; 2020.

7. Food and Agriculture Organization. FAO recommendations on planting and harvesting tasks during the COVID-19 outbreak using crop calendars. FAO; 2020.

8. Food and Drug Administration. Good manufacturing practice considerations for responding to COVID-19 infection in employees in drug and biological products manufacturing [Internet]. FDA; 2020.

9. COVID-19 updates and resources for the New Zealand fresh fruit and vegetable industry [Internet]. https://www.mpi. govt.nz/covid-19-information-andadvice/covid-19-and-food-safety/. 2020.

10. McClure P. Emerging pathogens of concern in in-pack heat-processed foods. In: Richardson P, editor. In-pack processed foods. Woodhead Publishing; 2008, pp. 229-50.

11. Ababouch L. Food safety assurance systems: Good practices in fisheries and aquaculture. In: Motarjemi $\mathrm{Y}$, editor. Encyclopedia of food safety. Waltham: Academic Press; 2014, pp. 159-67.

12. World Health Organization. Viruses in food: Scientific advice to support risk management activities. WHO; 2020.

13. Zhang H, Kang Z, Gong H, Xu D, Wang J, Li Z, et al. The digestive system is a potential route of 2019-nCov infection: A bioinformatics analysis based on singlecell transcriptomes. BioRxiv. 2020.

14. Zhou J, Li C, Zhao G, Chu H, Wang D, Yan $\mathrm{HH}-\mathrm{N}$, et al. Human intestinal tract serves as an alternative infection route for Middle East respiratory syndrome coronavirus. Sci Adv. 2017;3(11):eaao4966.

15. Holshue ML, DeBolt C, Lindquist S, Lofy $\mathrm{KH}$, Wiesman J, Bruce H, et al. First case of 2019 novel coronavirus in the United States. N Engl J Med. 2020;382(10):92936.

16. Letko M, Marzi A, Munster V. Functional assessment of cell entry and receptor usage for SARS-CoV-2 and other lineage $B$ betacoronaviruses. Nat Microbiol. 2020;5(4):562-9.

17. Cheung KS, Hung IFN, Chan PPY, Lung KC, Tso E, Liu R, et al. Gastrointestinal manifestations of SARS-CoV-2 infection and virus load in fecal samples from a Hong Kong cohort: Systematic review and meta-analysis. Gastroenterology. 2020;159(1):81-95.

18. Duda-Chodak A, Lukasiewicz M, Zięć G, Florkiewicz A, Filipiak-Florkiewicz A. Covid-19 pandemic and food: Present knowledge, risks, consumers fears and safety. Trends Food Sci Technol. 2020;105:145-60.

19. Ge X-Y, Li J-L, Yang X-L, Chmura AA, Zhu G, Epstein $\mathrm{JH}$, et al. Isolation and characterization of a bat SARS-like coronavirus that uses the ACE2 receptor. Nature. 2013;503(7477):535-8.

20. Hu B, Ge X, Wang L-F, Shi Z. Bat origin of human coronaviruses. Virol J. 2015;12(1):221.

21. World Health organization. Animal feed impact on food safety report of the FAO/ WHO expert meeting. WHO; 2008.

22. Wei G. Food safety issues related to wildlife have not been taken seriously from SARS to COVID-19. Environ Res. 2020;186:109605.

23. Yu P, Zhu J, Zhang Z, Han Y, Huang L. A familial cluster of infection associated with the 2019 novel coronavirus indicating possible person-to-person transmission during the incubation period. J Infect Dis. 
2020;221(11):1757-61.

24. Belouzard S, Millet JK, Licitra BN, Whittaker GR. Mechanisms of coronavirus cell entry mediated by the viral spike protein. Viruses. 2012;4(6):1011- 33.

25. Lam TT-Y, Jia N, Zhang Y-W, Shum MH-H, Jiang J-F, Zhu H-C, et al. Identifying SARS$\mathrm{CoV}-2$-related coronaviruses in Malayan pangolins. Nature. 2020;583(7815):282-5.

26. Azhar EI, El-Kafrawy SA, Farraj SA, Hassan AM, Al-Saeed MS, Hashem AM, et al. Evidence for camel-to-human transmission of MERS coronavirus. N Engl J Med. 2014;370(26):2499-505.

27. Wang L-F, Anderson DE. Viruses in bats and potential spillover to animals and humans. Curr Opin Virol. 2019;34:79-89.

28. Cauchemez S, Nouvellet $P$, Cori A, Jombart T, Garske T, Clapham H, etal. Unraveling the drivers of MERS-CoV transmission Proc Natl Acad Sci U S A. 2016;113(32):9081-6.

29. Memish ZA, Cotten M, Meyer B, Watson SJ, Alsahafi AJ, Al Rabeeah AA, et al. Human infection with MERS coronavirus after exposure to infected camels, Saudi Arabia, 2013. Emerg Infect Dis. 2014;20(6):10125.

30. Durai P, Batool M, Shah M, Choi S. Middle East respiratory syndrome coronavirus: Transmission, virology and therapeutic targeting to aid in outbreak control. Exp Mol Med. 2015;47(8): 181.

31. van Doremalen N, Bushmaker T, Karesh WB, Munster VJ. Stability of Middle East respiratory syndrome coronavirus in milk. Emerg Infect Dis. 2014;20(7):1263-4.

32. Franklin AB, Bevins SN. Spillover of SARS-CoV-2 into novel wild hosts in North America: A conceptual model for perpetuation of the pathogen. Sci Total Environ. 2020;733:139358.

33. Rabenau HF, Cinatl J, Morgenstern B, Bauer G, Preiser W, Doerr HW. Stability and inactivation of SARS coronavirus. Med Microbiol Immunol. 2005;194(1-2):1-6.
34. Tian S, Hu N, Lou J, Chen K, Kang X, Xiang Z, et al. Characteristics of COVID-19 infection in Beijing. J Infect. 2020;80(4):401-6.

35. Zhou P, Yang X-L, Wang X-G, Hu B, Zhang L, Zhang $\mathrm{W}$, et al. A pneumonia outbreak associated with a new coronavirus of probable bat origin. Nature. 2020;579(7798):270-3.

36. Gao QY, Chen YX, \& Fang JY. 2019 Novel coronavirus infection and gastrointestinal tract. J Dig Dis. 2020;21(3):125-6.

37. Ceylan Z, Meral R, Cetinkaya T. Relevance of SARS-CoV-2 in food safety and food hygiene: Potential preventive measures, suggestions and nanotechnological approaches. VirusDisease. 2020; 31(2): 154-60.

38. AW S. Vitamin C protects against coronavirus. OMNS. 2020:1-4.

39. Mongelli L, Golding B. New York hospitals treating coronavirus patients with vitamin C. New York Post Metro. 2020.

40. Martineau AR, Jolliffe DA, Greenberg L, Aloia JF, Bergman P, Dubnov-Raz G, et al. Vitamin D supplementation to prevent acute respiratory infections: Individual participant data meta-analysis. Health Technol Assess. 2019;23(2):1-44.

41. Wang L, Wang Y, Ye D, Liu Q. Review of the 2019 novel coronavirus (SARS-CoV-2) based on current evidence. Int J Antimicrob Agents. 2020;55(6):105948.

42. Harthill M. Review: Micronutrient selenium deficiency influences evolution of some viral infectious diseases. Biol Trace Elem Res. 2011;143(3):1325-36.

43. Te Velthuis AJ, van den Worm SHE, Sims AC, Baric RS, Snijder EJ, van Hemert MJ. $\mathrm{Zn} 2+$ inhibits coronavirus and arterivirus RNA polymerase activity in vitro and zinc ionophores block the replication of these viruses in cell culture. PLoS Pathog. 2010;6(11):e1001176.

44. Yin Y, Wunderink RG. MERS, SARS, and other coronaviruses as causes of 
pneumonia. Respirology. 2018;23(2):1307.

45. Ye Z-W, Yuan S, Yuen K-S, Fung S-Y, Chan C-P, Jin D-Y. Zoonotic origins of human coronaviruses. Int J Biol Sci. 2020;16(10):1686-97.

46. Chan JF-W, Yuan S, Kok K-H, To KK-W, Chu H, Yang J, et al. A familial cluster of pneumonia associated with the 2019 novel coronavirus indicating person-to-person transmission: A study of a family cluster. Lancet. 2020;395(10223):514-23.

47. Zhu Z, Lian X, Su X, Wu W, Marraro G \& Zeng Y. From SARS and MERS to COVID-19: a brief summary and comparison of severe acute respiratory infections caused by three highly pathogenic human coronaviruses. 2020; 21:224.

48. Hu B, Zeng L-P, Yang X-L, Ge X-Y, Zhang W, $\mathrm{LiB}$, etal. Discovery of a rich gene pool of bat SARS-related coronaviruses provides new insights into the origin ofSARS coronavirus. PLoS Pathog. 2017;13(11):e1006698.

49. Calisher CH, Childs JE, Field HE, Holmes KV, Schountz T. Bats: Important reservoir hosts of emerging viruses. Clin Microbiol Rev. 2006;19(3):531-45.

50. Burimuah V, Sylverken A, Owusu M, ElDuah P, Yeboah R, Lamptey J, et al. Seroprevalence, cross-species infection and serological determinants of prevalence of bovine coronavirus in cattle, sheep and goats in Ghana. Vet Microbiol. 2020;241:108544.

51. Verani M, Bigazzi R, Carducci A. Viral contamination of aerosol and surfaces through toilet use in health care and other settings. Am J Infect Control. 2014;42(7):758-62.

52. McDermott CV, Alicic RZ, Harden N, Cox EJ, Scanlan JM. Put a lid on it: Are faecal bioaerosols a route of transmission for SARSCoV-2? J Hosp Infect. 2020;105(3):397-8.

53. Mao K, Zhang H, Yang Z. Can a paperbased device trace COVID-19 sources with wastewater-based epidemiology? Environ Sci Technol. 2020;54(7):3733-5.

54. Medema G, Heijnen L, Elsinga G, Italiaander $\mathrm{R}$, Brouwer $\mathrm{A}$. Presence of SARS-Coronavirus-2 RNA in sewage and correlation with reported COVID-19 prevalence in the early stage of the epidemic in the Netherlands. Environ Sci Technol Lett. 2020;7(7):511-6.

55. Auwaerter PG. Coronavirus COVID-19 (SARS-CoV-2). Johns Hopkins ABX Guide. 2020.

56. Kampf G, Todt D, Pfaender S, Steinmann E. Persistence of coronaviruses on inanimate surfaces and theirinactivation with biocidal agents. J Hosp Infect. 2020;104(3):246-51.

57. Kwok YLA, Gralton J, McLaws M-L. Face touching: A frequent habit that has implications for hand hygiene. Am J Infect Control. 2015;43(2):112-4.

58. Cook N. Viruses in food and water: Risks, Surveillance, and Control. Elsevier; 2013.

59. Zhang Y, Chen C, Zhu S, Shu C, Wang D, Song J, et al. Isolation of 2019-nCoV from a stool specimen of a laboratory-confirmed case of the coronavirus disease 2019 (COVID-19). China CDC Weekly. 2020;2(8):123-4.

60. World Health Organization. COVID-19 and food safety: Guidance for food businesses. World Health Organisation; 2020a.

61. Peng X, Xu X, Li Y, Cheng L, Zhou X, Ren B. Transmission routes of $2019-\mathrm{nCoV}$ and controls in dental practice. Int J Oral Sci. 2020;12(1):1-6.

62. Otter JA, Donskey C, Yezli S, Douthwaite S, Goldenberg SD, Weber DJ. Transmission of SARS and MERS coronaviruses and influenza virus in healthcare settings: The possible role of dry surface contamination. J Hosp Infect. 2016;92(3):235-50.

63. Duan S-M, Zhao X-S, Wen R-F, Huang J-J, Pi G-H, Zhang S-X, et al. Stability of SARS coronavirus in human specimens and environment and its sensitivity to heating and UV irradiation. Biomed Environ Sci. 
2003;16(3):246-55.

64. World Health Organization. First data on stability and resistance of SARS coronavirus compiled by members of WHO laboratory network. WHO; 2020.

65. Aboubakr HA, Sharafeldin TA, Goyal SM. Stability of SARS-CoV-2 and other coronaviruses in the environment and on common touch surfaces and the influence of climatic conditions: A review. Transbound Emerg Dis. 2020;10(1111).

66. van Doremalen N, Bushmaker T, Morris DH, Holbrook MG, Gamble A, Williamson $\mathrm{BN}$, et al. Aerosol and surface stability of SARS-CoV-2 as compared with SARSCoV-1. N Eng J Med. 2020;382(16):1564-7.

67. Environmental Protection Agency. List N: Disinfectants for use against SARS-CoV-2 (COVID-19). EPA; 2020.

68. Shariatifar N, Molaee-Aghaee E. Novel coronavirus 2019 (COVID-19): Important tips on food safety. J Food Safe Hyg. 2020;5(1):58-9.

69. Food And Drug Administration. COVID-19 frequently asked questions. US: FDA; 2020

70. Food and Drug Administration. Food safety and the Coronavirus Disease 2019 (COVID-19). US: FDA; 2020

71. Center for Disease Control and Prevention. Guidance for cleaning and disinfecting public spaces, workplaces, businesses, schools, and homes. CDC; 2020.

72. Environmental Health \& Safety. COVID-19 prevention: Enhanced cleaning and disinfection protocols. Environmental Health \& Safety University of Washington; 2020.

73. Rabenau HF, Kampf G, Cinatl J, Doerr HW. Efficacy of various disinfectants against SARS coronavirus. J Hosp Infect. 2005;61(2):107-11.

74. Saknimit M, Inatsuki I, Sugiyama Y, Yagami K. Virucidal efficacy of physico-chemical treatments against coronaviruses and parvoviruses of laboratory animals. Jikken dobutsu Exp Anim. 1988;37(3):341-5.

75. Dellanno C, Vega Q Boesenberg D. The antiviral action of common household disinfectants and antiseptics against murine hepatitis virus, a potential surrogate for SARS coronavirus. Am J Infect Control. 2009;37(8):649-52.

76. Hudson JB, Sharma M, Vimalanathan S. Development of a practical method for using ozone gas as a virus decontaminating agent. Ozone Sci Eng. 2009;31(3):216-23.

77. Food Standards Scotland. COVID-19 guidance for food business operators and their employees. Scotland: Food Standards Scotland; 2020.

78. Food Standards Agency. Reopening and adapting your food business during COVID-19. Food Standards Agency; 2020.

79. Food And Drug Administration. Best practices for retail food stores, restaurants, and food pick-up/delivery services during the COVID-19 pandemic. US: Food And Drug Administration; 2020.

80. Food And Drug Administration. Good manufacturing practice considerations for responding to COVID-19 infection in employees in drug and biological products manufacturing. US: Food And Drug Administration; 2020.

81. United Nations Industrial Development Organization. Quality \& standards and their role in responding to COVID-19. UNIDO; 2020.

82. Center for Disease Control and Prevention. Healthier food retail (HFR) action uide. CDC; 2020.

83. Sportelli MC, Izzi M, Kukushkina EA, Hossain SI, Picca RA, Ditaranto N, et al. Can nanotechnology and materials science help the fight against SARS-CoV-2? Nanomaterials. 2020;10(4):802. 